\title{
Performance of Single Wire Earth Return Transformers with Amorphous Alloy Core in a Rural Electric Energy Distribution System
}

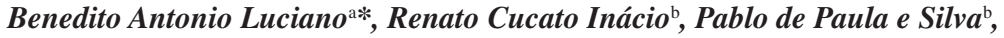 \\ Francisco das Chagas Fernandes Guerra ${ }^{\mathrm{a}}$, Raimundo Carlos Silvério Freire ${ }^{\mathrm{a}}$ \\ ${ }^{a}$ Departamento de Engenharia Elétrica, Universidade Federal de Campina Grande - UFCG, \\ Rua Aprígio Veloso, 882, CEP 58429-900, Campina Grande, PB, Brasil \\ ${ }^{\mathrm{b}}$ Companhia de Energia Elétrica do Estado de Tocantins, Palmas, TO, Brasil
}

Received: December 1, 2011; Revised: February 28, 2012

\begin{abstract}
In this paper are presented some considerations about the performance of single wire earth return amorphous alloy core transformers in comparison with conventional silicon steel sheets cores transformers used in rural electric energy distribution network. It has been recognized that amorphous metal core transformers improve electrical power distribution efficiency by reducing transformer core losses. This reduction is due to some electromagnetic properties of the amorphous alloys such as: high magnetic permeability, high resistivity, and low coercivity. Experimental results obtained with some single-phase, $60 \mathrm{~Hz}, 5 \mathrm{kVA}$ amorphous core transformers installed in a rural area electric distribution system in Northern Brazil have been confirming their superior performance in comparison to identical nominal rated transformers built with conventional silicon steel cores, particularly with regard to the excitation power and to the no-load losses.
\end{abstract}

Keywords: amorphous alloy, core losses, energy efficiency, transformer

\section{Introduction}

Single wire earth return (SWER) core transformers are characterized by having only one bushing on the high voltage side and two or more bushings on the low voltage side. Generally, these transformers are designed and constructed to be used in rural electricity distribution. Usually SWER core transformers are low-cost equipment and have apparent power of 5, 10 and $15 \mathrm{kVA}$.

The distribution of electricity power in rural areas has generally high cost of operation for the concessionary companies due to the seasonality of their loads. Under these conditions, the losses in the cores of the transformers manufactured with conventional grain oriented silicon steel become significant when these transformers operate in conditions of light load or no load. In such circumstances, part of the total current absorbed by the electric system is used in the magnetizing core transformers process. However, these losses can be reduced, which can be achieved by replacing the conventional by transformers for amorphous metal-based transformers, because it has been recognized that amorphous metal core transformers improve electrical power distribution efficiency by reducing excitation current and core losses ${ }^{1}$. This reduction is due to some electromagnetic properties of the amorphous alloys such as: high magnetic permeability, high resistivity, and low coactivity ${ }^{2}$.

In this paper are presented some experimental results obtained with SWER, $60 \mathrm{~Hz}, 5 \mathrm{kVA}$ amorphous core

*e-mail: benedito@dee.ufcg.edu.br transformers installed in a rural area electric distribution system, distant $50 \mathrm{~km}$ from Palmas (capital of the state of Tocantins), located in the Amazon region of Brazil.

From these results it can be observed the superior performance of amorphous core transformers in comparison to identical transformers manufactured with conventional cold-rolled grain-oriented (CRGO) silicon steel cores, particularly with regard to the excitation current and to the no-load losses. Before being installed, all transformers were submitted to test as stated at Brazilian Standards.

\section{From Academic Research to Electric Distribution Systems}

Chronologically, the development of amorphous alloys potentially applicable in transformer cores began in 1975. However, the introduction of these materials in the market only happened in 1976, with the first amorphous metal distribution transformer (AMDT), built at MIT's Lincoln Laboratory (USA). In that opportunity, a $30 \mathrm{kVA}$ transformer prototype, with an amorphous material core, was compared to a conventional silicon steel core transformer of equal nominal rated power. Once the comparative tests were carried out, the results obtained were favorable to AMDT, particularly in the aspects relative to the losses and the excitation current: there was a reduction of $60 \%$ in the total losses $(87.5 \%$ in the core losses and $21 \%$ in the copper losses) and the excitation current was reduced from 2.5 to $0.12 \mathrm{~A}$. However, in what concerns the weight, 
AMDT presented an increase of $15 \%$ in comparison to the conventional silicon steel core transformer ${ }^{3}$.

In the early 1980's, EPRI (Electric Power Research Institute, USA) and General Electric launched a project in which 25 units of pre-prototype $25 \mathrm{kVA}, 15 \mathrm{kV}$ amorphous metal core distribution transformers (AMDT) were tested for two years, followed by designing and testing 1000 units of the same size AMDTs on their distribution systems. The purpose of the field trial was to confer the long-term stability of core loss in amorphous metal transformers under actual operation conditions. Ten years later, there was an estimated 60000 to 70000 AMDT installed throughout the world.

In Brazil, the first studies and experimental tests had their origin in laboratories of some different institutions, in the early 1990's ${ }^{4}$, passing, soon after, to assembly by industrial manufacturers 5 .

\section{Experimental Procedure}

In Figure 1 are shown some units of $5 \mathrm{kVA}$ SWER transformers with amorphous alloy core $\left(\mathrm{Fe}_{78} \mathrm{~B}_{13} \mathrm{Si}_{9}\right)$ manufactured by Brazilian industries ITB. Seventeen of these transformers were submitted to open circuit and short circuit tests in the laboratory of the factory, in January 2009.

The following are listed the main electric characteristics of transformers under test:

- Rated power $\mathrm{kVA}=5$;

- Phases = 1;

- Frequency $=60 \mathrm{~Hz}$;

- High voltage side $(\mathrm{kV}): 20.90$ to 18.19 ;

- Low voltage side (V): 440/220;

- Rated current in high voltage side: $0.25 \mathrm{~A}$;

- Rated current in low voltage side: 11.36 A;

- Subtractive polarity.

All routine tests carried out in accordance with specific Brazilian Standards. But because the main interest is directly related to the energy efficiency in this paper are only presented two tests: no-load and short circuit.

\section{Results}

In Table 1 are presented the comparative values concerning losses and excitation current in single-phase 5 kVA transformers with maximum tension 24.2 and $36.2 \mathrm{kV}$, according to Brazilian Standard NBR 5440

The no-load losses and the excitation current measurements were performed at nominal frequency, applying rated voltage to the low voltage winding and leaving the high voltage in open circuit, as required by Brazilian Standard NBR 53567.

In Figure 2 are presented in graph form, the results of comparative tests between seventeen transformers with amorphous alloy core and seventeen transformers with CRGO silicon steel core, all with the same nominal power rating $(5 \mathrm{kVA})$.

\section{Discussion}

Since the excitation current is small, the Joule losses in the windings are negligible; the losses resulting from the process of magnetization and demagnetization of the

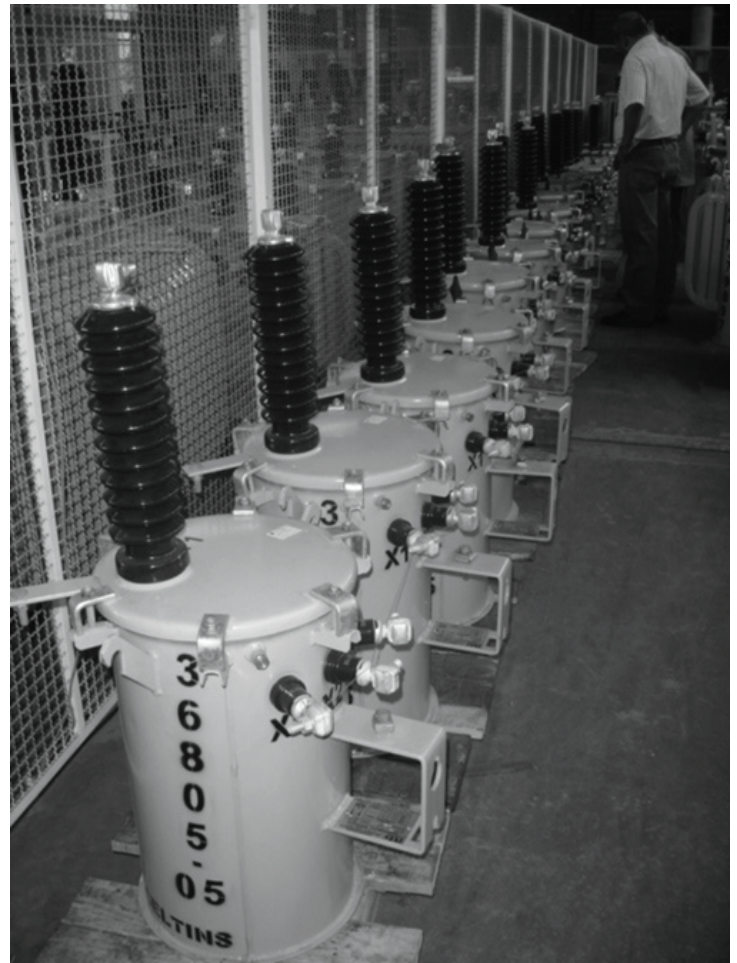

Figure 1. SWER amorphous core transformers in the factory environment.

Table 1. No-load losses comparison among amorphous and Si-Fe based-metal transformers.

\begin{tabular}{cccc}
\hline Tests & Amorphous & $\begin{array}{c}\text { Silicon } \\
\text { steel }\end{array}$ & $\begin{array}{c}\text { Values according to } \\
\text { NBR 5440 }\end{array}$ \\
\hline $\begin{array}{c}\text { No-load } \\
\text { loss (W) }\end{array}$ & 8 & 36 & 50 \\
$\begin{array}{c}\text { Excitation } \\
\text { current (A) }\end{array}$ & 0.13 & 0.36 & 4.8 \\
\hline
\end{tabular}

core are significant. In analytical terms, these losses are characterized as hysteresis, eddy currents and anomalous losses.

The hysteresis loss is directly proportional to the frequency of supply voltage and eddy current loss is directly proportional to the square of the frequency of the source. This is the reason why this test should be conducted at nominal frequency.

Physically, the reason for the excitation current is small compared to the nominal current of the winding, due to the fact that the no-load transformer can be represented by a high-impedance load with respect to the power supply. And this impedance will be greater the larger the magnetic permeability and electrical resistivity of core material.

In the specific case of amorphous $\mathrm{Fe}_{78} \mathrm{~B}_{13} \mathrm{Si}_{9}$ used in the cores of transformers these values are higher than the values for GO FeSi alloys used in conventional transformers. Therefore, the maximum relative magnetic permeability of amorphous $\mathrm{Fe}_{78} \mathrm{~B}_{13} \mathrm{Si}_{9}, 60 \mathrm{~Hz}$, is around 70000, while the value of this quantity for the $\mathrm{GO} F \mathrm{FeSi}$ at $60 \mathrm{~Hz}$, is around 40000 . Since the value of the electrical resistivity 
Table 2. Comparison of short-circuit test values obtained with amorphous and CRGO silicon steel core transformers.

\begin{tabular}{cccc}
\hline $\begin{array}{c}\text { Short-circuit } \\
\text { test }\end{array}$ & Amorphous & $\begin{array}{c}\text { Silicon } \\
\text { steel }\end{array}$ & $\begin{array}{c}\text { Values according } \\
\text { to NBR 5440 }\end{array}$ \\
\hline Losses (W) & 118 & 100 & 120 \\
Current (A) & 0.25 & 0.24 & 0.25 \\
Voltage (V) & 536.05 & 527.34 & - \\
\hline
\end{tabular}

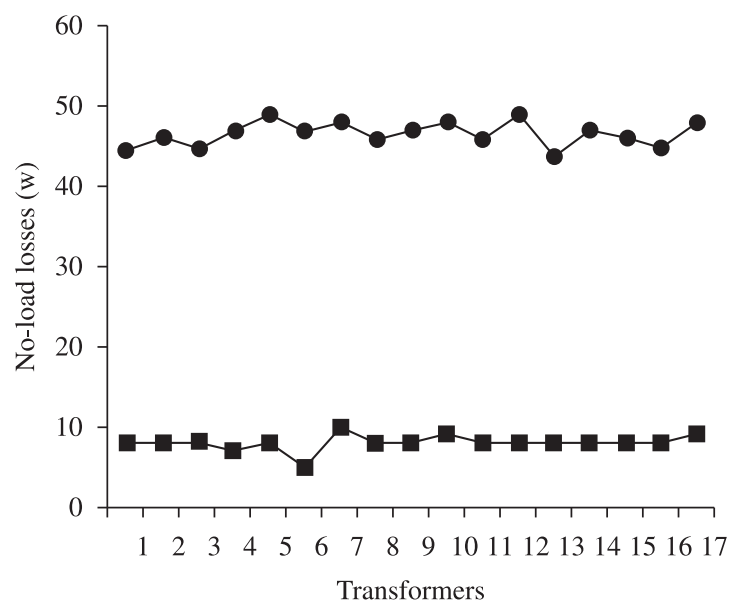

- $\mathrm{Fe}-\mathrm{Si}$ amorphous

Figure 2. Comparison of core losses between SWER amorphous core transformers and CRGO silicon steel core transformers.

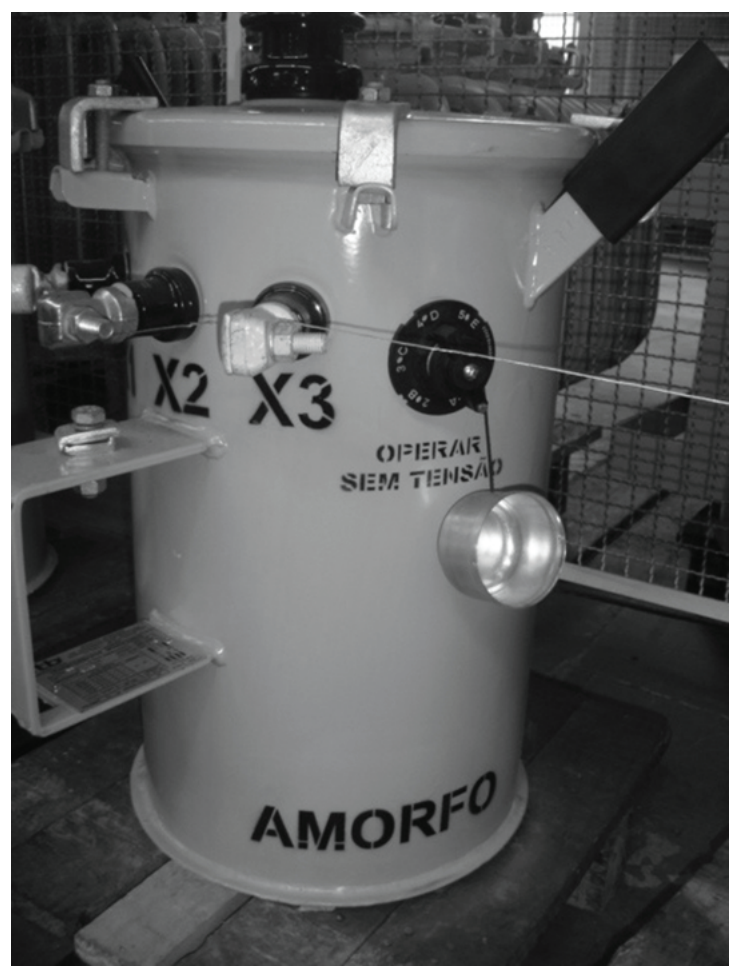

Figure 3. SWER amorphous core transformer with low voltage terminals short-circuited.

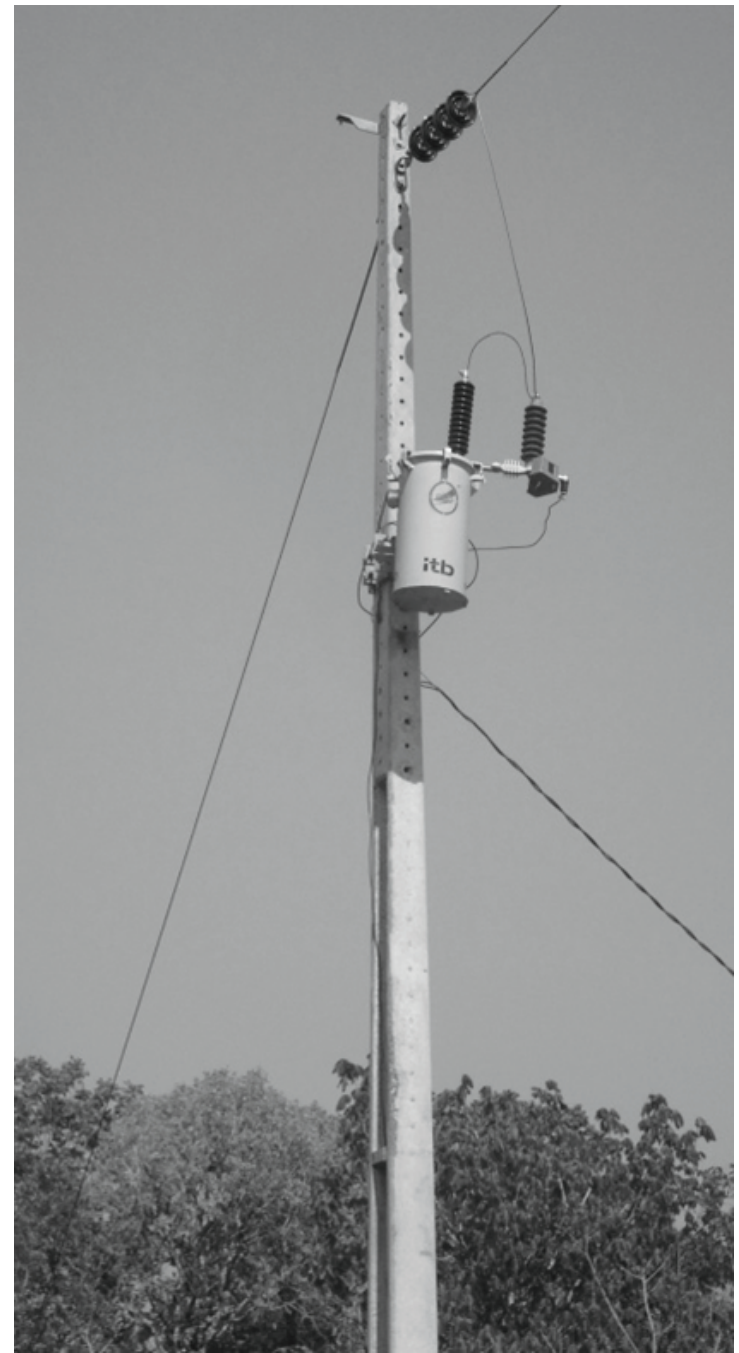

Figure 4. SWER amorphous core transformer installed in the rural zone.

of amorphous $\mathrm{Fe}_{78} \mathrm{~B}_{13} \mathrm{Si}_{9}$ is between 130 to $135 \mu \Omega$.m, while the value of this magnitude for the GO FeSi is around 10 to $47 \mu \Omega$.m. Note that the high value of relative permeability provides a better magnetic coupling and the high value of electrical resistivity results in smaller eddy current losses in the core.

Note also that although both transformers have values of excitation current and load loss values below the Brazilian Standard NBR 5440 recommended, it appears that the values of the excitation current $(0.13 \mathrm{~A})$ and no-load losses $(8 \mathrm{~W})$ for transformers with amorphous core transformers are lower than values of the conventional transformers, that are $0.36 \mathrm{~A}$ and $36 \mathrm{~W}$, respectively.

The measurement of short circuit losses was performed at nominal frequency, connecting the high voltage terminals to the source and at the same time keeping the low voltage windings short-circuited, as shown in Figure 3.

In Table 2 are presented the comparative values concerning short-circuit test in single-phase $5 \mathrm{kVA}$ 
transformers with maximum tension 24.2 and $36.2 \mathrm{kV}$, according to Brazilian Standard NBR 5440 ${ }^{6}$.

As can be seen in Table 2, there are virtually no differences between the values obtained in short-circuit test for both types of transformers. This, in fact, was expected, since the active losses relate to the Joule effect in the windings and has no dependence on the magnetic material core and short-circuit current depends on the impedance of a short circuit.

After submitted to routine tests in the laboratory, the seventeen $5 \mathrm{kVA}$ SWER amorphous core transformers were installed in a rural area electric distribution system in Northern Brazil, located $50 \mathrm{~km}$ from Palmas city, capital of a Brazilian state called Tocantins. Figure 4 shows a photograph of one of these transformers.

The choice of the rural zone was due to the low load factor in that area, where the transformer operate most of the time with reduced loading and core losses are preponderant to the copper losses, for long periods.

In the SWER systems it is important to observe the earth resistance value to avoid shocking people and animals that might be in the area. Animals can feel electric current at low voltage (some at $5 \mathrm{~V}$ or lower). For $5 \mathrm{kVA}$ distribution transformer the maximum earth resistance is $20 \Omega^{8}$.

\section{Conclusion}

The experimental results obtained with the single wire earth return amorphous alloy core transformers in comparison with conventional FeSi core transformers used in rural electric energy distribution network have been confirming their superior performance, particularly with regard to the excitation power and to the no-load losses.

Therefore, replacement of conventional transformers with cores of cold-rolled-oriented silicon steel (CRGO) by transformers with amorphous alloy core can mean energy conservation and environmental preservation, contributing to the reduction of need for building new power plants and their environmental impacts. In the case of hydroelectric plants, ecological and social impacts, and in case of power plants, lower fuel consumption and emissions. In the latter case, the benefits of conservation can be characterized by significant reduction in emissions of greenhouse gases such as sulfur dioxide $\left(\mathrm{SO}_{2}\right)$, nitrogen oxides $\left(\mathrm{NO}_{\mathrm{x}}\right)$ and carbon dioxide $\left(\mathrm{CO}_{2}\right)$.
Regarding the cost, currently in Brazil distribution transformers are manufactured and marketed with amorphous alloy cores at prices equivalent to those of conventional transformers with CRGO cores.

\section{Acknowledgements}

The authors wish to express their thanks to Professor Antonio Flávio Licarião Nogueira (State University of Santa Catarina - UDESC, Brazil) for the offered suggestions during the elaboration of this work. They are also thankful to ANEEL, CELTINS, ITB, CNPq, and CAPES (Brazil).

\section{References}

1. Hasegawa R and Azuma D. Impacts of amorphous metal-based transformers on energy efficiency and environment. Journal of Magnetism and Magnetic Materials. 2008; 320:2451-2456. http://dx.doi.org/10.1016/j.jmmm.2008.04.052

2. Ogawa Y, Naoe M, Yoshizawa Y and Hasegawa R. Magnetic properties of high $B_{\mathrm{s}}$ Fe-based amorphous material. Journal of Magnetism and Magnetic Materials. 2006; 304:675-677. http://dx.doi.org/10.1016/j.jmmm.2006.02.167

3. Anantharaman TR and Suryanarayana C. Rapidly Solidified Metals - A Technological Overview. Switzerland: Trans Tech Publications; 1987.

4. Luciano BA and Kiminami CS. Single phase 1-kVA amorphous core transformer: design, experimental tests, and performance after annealing. IEEE Transactions on Magnetics, 1999; 35(4):2152-2154. http://dx.doi. org/10.1109/20.774186

5. Luciano BA, Nóbrega RS, Santos MBG and Cavalcanti LF. Amorphous alloy core transformers: an experience in the Celb rural distribution system. In: Proceedings of the International Congress and Exhibition on Electrical Distribution - Cidel; 2002; Buenos Aires, Argentina. Buenos Aires; 2002. p. 1-6.

6. Associação Brasileira de Normas Técnicas - ABNT. NBR 5440: Transformadores para redes aéreas de distribuição - Padronização. ABNT; 1999

7. Associação Brasileira de Normas Técnicas - ABNT. NBR 53561: Transformadores de potência - Parte 1: Generalidades. ABNT; 2007.

8. Chapman N. When one wire is enough. Transmission and Distribution World. 2001; 53(4):56. 